\title{
Disfagia em idosos e os agenciamentos corporal/emocional: reflexões teórico-prática sobre como estamos tratando
}

\section{Dysphagia in elderly and the corporal / emotional assemblages: theoretical-practical reflections on how we are dealing with it}

\author{
${ }^{1}$ Lijamar de Souza Bastos lijamar.bastos@ig.com.br \\ ${ }^{1}$ Ricardo Luiz Ramos \\ ${ }^{1}$ Paulo Sergio Silva \\ ${ }^{2}$ Marcelo Alves Paraiso \\ ${ }^{2}$ Ilda Cecíla Moreira da Silva \\ ${ }^{3}$ Nébia Maria de Almeida Figueiredo
}

\section{RESUMO}

O presente artigo apresenta um ensaio reflexivo relacionado aos sentimentos dos idosos diante das dificuldades de deglutição (disfagia/presbifagia). Tem como proposta, colaborar com a literatura e a prática neste campo, norteando ações e condutas fonoaudiológicas preventivas e de reabilitação no âmbito multidisciplinar. Assim, o objetivo do estudo é discutir como os idosos se sentem e quais são os efeitos da disfagia em seu corpo físico e emocional diante da possibilidade e/ou ação de dificuldade de deglutição. Abordamos os agenciamentos de cuidados em saúde na abrangência de um corpo anatômico, fisiológico, biológico, subjetivo e emocionalpermeado por fatores históricos e socioculturais. Tal perspectiva busca superar a mera correlação biológica anatomia/fisiologia, ou seja, a localização/função,pois sofremos influências do mundo exterior, das relações políticas e sociais dos corpos que cuidam, podendo implicar na evolução, na construção de conhecimento científico, nas práticas de intervenção e tratamentofonoaudiológicorelacionadas às dificuldades de deglutição.

Palavras-chave: disfagia, agenciamento, subjetividade, corpo.

\begin{abstract}
This article presents a reflective essay related to the feelings of the elderly before swallowing difficulties (dysphagia / presbifagia). Its proposal, collaborating with literature and practice in this field, guiding preventive actions and conduct speech therapy and rehabilitation in a multidisciplinary context. The objective of the study is to discuss how older people feel and what are the effects of dysphagia on their physical and emotional body at the possibility and / or action of swallowing difficulty. We address the assemblages of health care coverage in ananatomical, physiological, biological, subjective and emotional body permeated by historical and sociocultural factors. This perspective seeks to overcome the mere anatomy / physiology, ie, the location / biological correlation function, we suffer influences of the outside world, the political and social relationships that take care of the bodies, which may involve the evolution in the construction of scientific knowledge, practices intervention and speech therapy related to swallowing difficulties.
\end{abstract}

Keywords: dysphagia, agency, subjectivity, body.

\footnotetext{
1 Universidade Federal do Estado do Rio de Janeiro - UniRIO.

2 Centro Universitário de Volta Redonda - UniFOA.

3 Universidade Federal do Estado do Rio de Janeiro - UniFOA.
} 


\section{INTRODUÇÃO}

No Brasil, é definida como idosa a pessoa que tem 60 anos ou mais de idade (MS, 2010). A expectativa de vida vem elevando-se, principalmente com o fomento de inovações nas áreas de saúde. Atualmente existe no Brasil, aproximadamente, 20 milhões de pessoas com idade igual ou superior a 60 anos, o que representa pelo menos 10\% da população brasileira (ibid). Segundo Figueiredo; Santos; Tavares (2012), tendo como referência o Censo Demográfico realizado pelo Instituto Brasileiro de Geografia e Estatística (IBGE) em 2010, “estimativas apontam que serão 32 milhões de idosos no país em 2025, deixando o Brasil em sexto lugar no ranking de países com maior número de idosos no mundo" (p.3).

Na intenção de atingir o objetivo proposto -discutir como os idosos se sentem e quais são os efeitos da disfagia em seu corpo físico e emocional diante da possibilidade e/ou ação de dificuldade de deglutição- foi utilizada a pesquisa bibliográfica (SEVERINO, 2007, p. 122),na busca de citações de autores que desenvolveram estudos similares à esta temática, portanto, convidamos à reflexão destas. Logo, a natureza metodológica deste artigo é o estudo de revisão bibliográfica a partir de referências teóricas publicadas(CERVO; BERVIAN, 2002, p. 65), com uma abordagem descritiva.

Neste contexto, torna-se relevante os estudos sobre essa crescente população e suas especificidades, dentre elas, a habilidade e a coordenação reduzida no ato de deglutir alimentos ou saliva.Na literatura, a idade avançada é considerada um fator de risco para as alterações de deglutição (MENDES et al., 2012). Os idosos dispõem de recursos anatomofuncionais reduzidos e a eficiência da funcionalidade da deglutição acontece por meio de compensações como, por exemplo, o aumento de trânsito do alimento ingerido (ibid).

A degeneração fisiológica do mecanismo da deglutição ou presbifagia, como sinais da senescência, ocorre em todas as fases da deglutição, devido às mudanças estruturais, anatômicas e funcionais interferindo no mecanismo da deglutição no idoso sadio.

Além disso, é preciso considerar outro desafio qualitativo que se refere às questões socioculturais que nos permeiam. Vivemos numa sociedade onde alguns momentos da refeição, tornam-se oportunidades de lazer, celebração, confraternização, comemoração, reunião entre família e amigos. Portanto, estabelecer a alimentação por via oral de forma segura é uma expectativa frente ao quadro de disfagia em idosos - a presbifagia. Neste contexto, a atenção e os cuidados são específicos, considerando que o processo de envelhecimento não ocorre de forma homogênea em todo ser humano. As alterações orgânicas e emocionais, dificuldades e subjetividades podem variar neste processo, provocando o isolamento social. Entendendo que a subjetividade humana "é construída historicamente" (FIGUEIREDO; MACHADO, 2009, p. 390), as influências ambientais e socioculturais que permeiam nosso corpo, o corpo que cuida (fonoaudióloga) e o corpo que recebe os cuidados (cliente), serão abordados enquanto "corpo-saúde” compartilhando sentimentos, emoções na produção de subjetividades (ibid).

Se a alimentação é fundamental para a nutrição e a nossa sobrevivência, o ato de deglutir parece ser automático, porém requer uma sequência complexa, integrada e coordenada de atividades neuromusculares programadas no centro medular da deglutição. Por isso, é importante o conhecimento de algumas estruturas anatômicas do corpo, como a cavidade oral, faringe, laringe e esôfago, no qual transporta o bolo alimentar até o estômago. Esse mecanismo anatômico e fisiológico da deglutição deve ser atentamente acompanhado, orientado e controlado. Qualquer interferência ou dificuldade no processo de deglutição, em que denominamos de disfagia, merece ações e atos de cuidar específicos para prevenção e/ou reabilitação desses sinais e sintomas disfágicos. O conhecimento do "corpo biológico" e suas diversas significações definido por Figueiredo; Machado (2009) ou de um corpo "anatomo-clínico" definido por Foucault (2003), é importante quando não apartado de seus componentes emocionais, subjetivos, históricos, espirituais, culturais, cognoscentes e singulares. Nesta perspectiva, os autores trazem para reflexão o conceito de corpo inteiro, racional e sensível, segundo Figueiredo; Machado (2009) e a referência de corpo sem órgãos (CsO) discutido por Deleuze e Guattari (1997), nos proporcionando instrumentos essenciais nas práticas de cuidados em saúde. 
A partir de convicções políticas e epistemológicas que embasam tais conceitos concebidos pelos seus praticantes (o corpo que cuida e o corpo que recebe os cuidados), exige a compreensão de que teoria e prática são instâncias complementares e indissociáveis do fazer/pensar dos sujeitos que vivenciam determinado espaço e tempo. Essa ótica concebe essa relação, sujeito e instituições, como sendo uma tessitura, um enredamento, onde exige uma interpenetração permanente não devendo ser percebidos como elementos separados da realidade ou de qualquer reflexão.

Então, como os idosos se sentem e quais são os efeitos da disfagia em seu corpo físico e emocional diante da possibilidade e/ou ação de dificuldade de deglutição? Numprograma de prevenção e reabilitação da disfagia em idosos - presbifagia - pode-se cogitar que as emoções vividas na dificuldade de deglutir são sintomas a serem considerados?

Portanto, o presente ensaio reflexivobusca superar o olhar dicotômico e cartesiano que analisa o corpo como uma estrutura anatomofisiológica, para compreendê-lo na perspectiva da corporeidade. Compreender o corpo que está sendo cuidado na perspectiva mencionada - corporeidade - requer concebê-lo em sua inação (NAJMANOVICH, 2001), em se processo de constituição: passado, presente e futuro. Ao considerar tal possibilidade, percebemos o idoso em seu processo de se constituir humano, seus anseios, suas necessidades, seus medos, seus desejos, seus afetos e suas emoções. Assim, o corpo é compreendido a partir dos aspectos complexos que compõem as suas experiências enquanto sujeito em um mundo vivido, sofrendo o impacto da sociedade, da cultura, da economia e da política em que encontra-se imerso, mas que também age e influencia tal realidade.

Neste cenário,buscamos superar o olhar que visualiza apenas a faringe, a laringe, dentre outras partes do corpo, para olhar o sujeito e acreditar que suas emoções são indicadores de intervenções. É possível nos interessarmos pelo corpo como fonte de vida, de prazer e de desejo, que é memória e história, que tem saber e muitas outras combinações de ser e de viver, mesmo estando idoso. Emoções como as intensidades corporais que se expressam subjetivamente e podem nos indicar novos modos de diagnosticar ou tratar a disfagia.

\section{AS EMOÇÕES NA DINÂMICA DA VIDA E OS AGENCIAMENTOS DO CORPO}

A nossa formação é intensamente fundamentada num conhecimento científico-biomédico que tenta dar conta de um discurso de saúde, baseado no diagnóstico e tratamento de sinais e sintomas da doença. Aparentemente é um olhar racional para o que éconcreto, visível e mensurável no corpo.

Isso reflete o paradigma da modernidade, cujo princípio do Mercado pauta-se na racionalidade cognitivo-instrumental da ciência e da tecnologia (SANTOS, 2010); a cientificização era a solução e a verdade aceita sem contestação pela sociedade, como uma hierarquia cognitiva prepotente subordinada a modelos e saberes científicos explicativos de diversos fenômenos ou problemas. As formas científicas, nessa configuração paradigmática, são construídas para representar e interpretar as coisas de natureza complexa, na busca de uma ordenação do mundo.

Superar as concepções do paradigma moderno que influenciam o olhar clínico racional, nos aproximando da perspectiva proposta, é adotar, de acordo com Santos (2007) uma ecologia de saberes, cuja “epistemologia destabilizadora" (p. 32) permite transformar o conformismo em "perguntas constantes e respostas incompletas" (p. 34), pois se nega a compreender o mundo por intermédio de uma única racionalidade, na qual denomina de razão indolente.

Santos (2010), menciona que a racionalidade indolente ao conceber o mundo a partir de uma única forma de interpretação da realidade, exclui a diversidade de práticas culturais e saberes que atuam no mundo. $\mathrm{O}$ autor denomina esta forma de pensamento abissal, pois a razão indolente constrói uma separação significativa destas 'outras' formas de interpretação do mundo, tornando-as incapaz de conviver.

Diante do exposto, cabe perguntar: qual seria o impacto de uma concepção pós abissal deconhecimento (ecologia de saberes) sobre as condutas clínicas e centros de investigação? 
Esta interrogação nos leva a refletir e a caminhar em busca de ações clínicas que rompam com o paradigma moderno apresentando potenciais emancipatórios, o que nesse estudo, se apresenta por meio de considerações sobre as questões emocionais no processo disfágico/presbifágico.

Pensar na direção supracitada, movimenta-nos em direção às ideias de Boaventura de Souza Santos (2010) e ao pensamento pós abissal. Para o autor, o referido pensamento caminha em direção contrária à razão indolente, não aceitando aótica que atua na perspectiva monocultural, hegemônica, como se fosse uma referência e modelo para todas as outras culturas e formas de conhecimento.

Dessa forma, compreender a necessidade de enredar teoria e prática, anatomofisiologia e sentimentos (e emoções), requer uma aproximação ao princípio da incompletude. Para Santos (2010) o princípio é condição da possibilidade do diálogo e debate epistemológico entre diferentes formas de conhecimento. $\mathrm{O}$ autor salienta que o que cada saber e 'perceber' contribui para tal diálogo e é o que importa para a superação de uma dada ignorância, pois todos os saberes possuem limites internos e externos. Os limites externos são as limitações que emergem da relação com o mundo e das respostas que esse conhecimento pode oferecer para superar os problemas que dele advém. Os limites externos "resultam do reconhecimento de intervenções alternativas tornadas possíveis por outras formas de conhecimento" (p. 107), O autor ainda ressalta que é muito comum os saberes reconhecerem apenas seus limites internos. Assim, o que se apresenta é o reconhecimento de uma possível superação da lógica monocultural do saber científico, “com a ideia de que os saberes não científicos são alternativas ao saber científico” (p. 107).

Incluir emoções e sentimentos nos aspectos que conhecemos, às vezes, parece com algo impreciso ou com fenômenos subjetivos, até porque temos esquecido o cérebro como o centro de tudo que acontece conosco, seja de ordem objetiva ou de ordem subjetiva. Nessa categoria dos fenômenos imprecisos não há exatidão e, portanto “sem regras e sem leis, é anômico e rejeitado do reino da ciência” (MOLES, 1995, p. 17).

No que concerne às emoções, as funções neurológicas superiores ou “processos mentais superiores” estudada por Vygotsky (2006) refere-se à linguagem, aprendizagem, memória, atenção, pensamento, gnosias/percepções, comportamento emocional, que propiciam a cognição e as relações sociais interpessoais. Tais funções nos integram ao ambiente e ao mundo, fazem parte do processo de aprendizagem na vida cotidiana e devem ser lembradas nas intervenções com os idosos. Para o autor, a emoção interfere na cognição e vice-versa.

Ainda, durante o ciclo de vida, o nosso cérebro é capaz de aprender coisas novas, considerando as experiências adquiridas no meio sociocultural, os estímulos ambientais 'empobrecidos' ou 'enriquecidos' e as circunstâncias emocionais influenciando no desenvolvimento cerebral. Isso é plasticidade cerebral ou neuroplasticidade, cujas definições são "a capacidade do sistema nervoso central em modificar sua organização estrutural própria e de funcionamento em resposta a condições mutantes, aprendizados e a estímulos repetidos” (FERREIRA, 2009, p. 56), ou ainda "é uma propriedade inerente ao sistema nervoso com a capacidade de modificar o seu funcionamento e de se reorganizar através de alterações ambientais ou de lesão” (WAJNSZTEJN, 2009, p. 30).

Por isso, e, provavelmente, ao estar diante de um idoso, precisamos acreditar que ele tem um cérebro em ação, plástico, que precisa sobreviver no mundo, no qual cumpre seus compromissos como ser biológico e social.

Uma questão particular, nesse estudo reflexivo, pode fazer a diferença, o recorte, o novo quando associamos o 'alimentar-se' no sentido do paladar e o medo por disfunção orofaríngeo-esofágico. Assim, a tríade alimento-medo-sentimento que tem como base de ação e intervenção na emoção que ele sente diante da possibilidade de engasgar, isto é, alimentar-se passa a ser uma situação de perigo, tornando uma atividade social e prazerosa em um momento de tensão e fuga do perigo.

Quanto a isso, LeDoux (2001) nos diz: 
as emoções nada mais são do que características unicamente humanas e que, na verdade, alguns sistemas emocionais no cérebro são fundamentalmente e similares a um grande número de criaturas dotadas de espinha dorsal (...); ao tentar descobrir o que há de singular na emoção, ele tenta analisar de que maneira a evolução mantém, tenazmente, as funções emocionais da espécie, enquanto vai modificando muitas outras funções cerebrais e características físicas (LEDOUX, 2001, p. 97).

Quando falamos da lembrança de engasgar e ter o medo, temos pensado no cérebro com suas funções cognitivas superiores, como um processamento em rede, que está guardado no corpo e que ressurge diante do perigo - o alimento. Poderemos estar falando de cognição, mas segundo LeDoux (2001)

as emoções enquanto cognições nada significam, ou ao menos não guardam um significado especialmente emocional. Nossas emoções são repletas de sangue, suor e lágrimas, mas isto não seria evidente após a análise da moderna pesquisa cognitiva das emoções (...). A maneira mais natural de pensar as emoções é que a percepção mental de certos fatos (em nosso estudo: a hora de alimentar-se) estimula a disposição mental chamada emoção e que este estado de espírito dá origem a expressão corporal (ibid, p. 39) grifo nosso.

Conjecturamos que o idoso diante do alimento, percebe-o como um fator estimulante e é nesse momento que ocorre a emoção impregnada de combinações entre prazer e medo, e desencadeando a sequência de estímulo-sentimento. Em relação a isto, as mudanças corporais decorrem diretamente da percepção de fatos, e a nossa sensação das mesmas mudanças no momento em que ocorrem a emoção (LEDOUX, 2001, p. 40).

Ao considerar as emoções como desencadeadores de expressões corporais na presbifagia, estamos trazendo para a cena de cuidar de clientes idosos, elementos imprecisos, embora reais, para o discurso da racionalidade sobre músculo/ envelhecimento/ engasgo. As sensações são reais e acompanham aspectos físicos, sensações físicas, respostas fisiológicas, numa idade que já é marcada por inúmeras dificuldades de viver. Os elementos ou fenômenos imprecisos são “fatos científicos no sentido próprio (...), flutuantes, e difíceis de delimitar” (MOLES,1995, p. 26).

Assim, uma posição é necessária: não há como esquecer esse sujeito emocional que é o idoso e os riscos de desenvolver um estudo que pode perder de vista uma racionalidade científica para dar conta da emoção. Acreditamos que as emoções básicas devem ser consideradas no programa de prevenção e reabilitação fonoaudiológicada disfagia em idosos - presbifagia. Estas emoções básicas podem ser agenciadoras de expressões corporais a serem abalizadas quando cuidamos, nas instabilidades dos acontecimentos. E como estamos agenciando estes idosos no espaço de cuidar? Como perceber as emoções num cenário de investidas técnicas e tecnológicas, por vezes estressantes?

Segundo Santos (1999), neste espaço onde todos nos encontramos, mergulhados em novos caminhos tecnológicos, adquire-se um conjunto de esquemas indissociáveis entreobjetos e ações. Para o autor, tais sistemas configuram uma paisagem com objetos naturais, objetos fabricados pelo homem e diversas ações correlacionadas a este espaço produtivo e transformador. $\mathrm{O}$ autor ainda indica que neste espaço conectado com a paisagem renovam-se e adaptam-se, constantemente, às novas necessidades humanas.

No entanto, para Deleuze; Guattari (1995) o agenciamento é constituído inseparavelmente pela expressão (agenciamento coletivo de enunciação) e pelo conteúdo (agenciamento maquínico), desta forma, "a expressão refere-se ao conteúdo sem descrevê-lo ou representá-lo, mas intervém nele” (SOARES; MIRANDA, 2008, p. 7).

Idosos territorializados no campo da saúde e da família submetidos às ações de cuidar, produzem também um espaço de subjetividades. Somos, portanto, instigados a entrar nesses corpos-máquinas produtoras de subjetividades sobre a vida, a saúde, a doença, a terceira idade, do mesmo modo que nós, os profissionais de saúde, também somos produtores de novas subjetividades quando nos encontramos com eles.

Em meio ao capitalismo desenfreado e aos modelos racionais dominantes que, muitas vezes insistem em colocar os idosos à margem, ainda é possível pensarmos em produção de subjetividades singulares, escapando 
aos padrões oferecidos inexoravelmente pela mídia e outros pares. Em oposição ao sistema e estrutura que convivemos cotidianamente, Guattari (2013) sugere,

(...) se constituir, se definir e se desterritorializar. Esses processos de 'se pôr a ser' dizem respeito apenas a certos subconjuntos expressivos que romperam com seus encaixes totalizantes e se puseram a trabalhar por conta própria e a subjugar seus conjuntos referenciais para se manifestar a título de indícios existenciais, de linha de fuga processual (GUATTARI, 2013, p. 28).

Logo, é relevante compreender que os idosos não são apenas um aglomerado desubjetividades individuais, mas uma rede de subjetividades que produzem um contexto social, já que eles crescem significativamente em termos populacionais e possivelmenteencontram-se em todos os níveis de produção e consumo.

O que queremos salientar é que um idoso saudável é também uma máquina, na perspectiva deleuziana,que sonha, devaneia, deseja e desenvolve modos singulares de ser, ou seja, é capaz de recusar modos estabelecidos de codificação para eles. Modos de manipulação, de comando, de subestimação. Podem e fazem um movimento de recusa para construir outros modos de sensibilidade, de relação com o outro, de produção de coisas, ações e saberes sobre eles; de criatividade que dê conta do desprezo, do gosto de viver, de continuar construindo o mundo até onde for possível. Logo, o idoso também é uma máquina desejante que ameaça transbordar, pois o corpo é uma composição molecular aberta, em movimento. Segundo Deleuze (1997) desejar é construir um agenciamento, é revolucionário, pois não está em direção ao ideal e, às vezes pequenos desencaixes se fazem necessários. Ao contrário do mundo das ideias do filósofo grego Platão, desejo não é falta, mas produção no mundo real produz o real, é válida por si próprio e não se esgota.

Esses idosos dos quais temos interesse de cuidar na intenção de prevenir ou reabilitar a presbifagia, podem nos ajudar nesse estudo a instaurar dispositivos para mudar modos de cuidar, modos de nos aproximar, modos de diagnosticar, modos de prevenir a presbifagia.

Ao colocar em prática a produção de um tipo de subjetividade - da ordem da emoção - como elemento norteador num programa de prevenção e reabilitaçãofonoaudiológica da presbifagia, é no mínimo um desafio mais teórico do que prático, no qual segundo Guattari; Rolnik (1996)

é colocar em prática um tipo de processo de subjetivação diferente do capitalístico, com seu duplo registro de produção de valores universais por um lado, e de 'reterritorialização' em pequenos guetos subjetivos (os idosos, minorias sociais, raciais, sexuais, etc), por outro lado” (GUATTARI; ROLNIK, 1996, p. 22) (grifo nosso).

Olhar o idoso na perspectiva de gueto é saber que associá-lo a agenciamentos, pode dar conta de uma dimensão molar/molecular como grupo de interesse social, de políticas públicas, de instalação de um programa que inclui sistemas de percepção, desejo, sensibilidade e afetos. Os idosos também produzem sentidos não centrados em agentes individuais (no funcionamento de instâncias intrapsíquicas, egoicas, microssociais), nem em agentes grupais. De acordo com Guattari; Rolnik (1996), eles podem ser entendidos como máquinas de expressão que podem ser tanto de natureza extra pessoal, extra individual - referimo-nos a sistemas máquinicos, econômicos, sociais, tecnológicos, icônicos, ecológicos, etológicos, de mídia, enfim, sistemas que não nos são mais imediatamente antropológicos - quanto de natureza intra-humana, intrapsíquica, intrapessoal (ibid, p. 31). Neste caso, aludimos a sistemas de percepção, sensibilidade, afeto, desejo, representação, imagens, valor, modos de memorização e produção de ideias, de sistemas de inibição e de automatismos, sistemas corporais, orgânicos, biológicos, fisiológicos, etc.

Recusando esses modos de manipulação, controle e subjetividade massificada, torna-se relevante considerar no idoso a qualidade de vida inerente a valores, emoções e desejos próprios, não universais, mas singulares cognitivamente. Considerar os modos de produção singulares que escapem ao aprisionamento imposto silenciosamente, resga- 
tando o gosto de viver e de construir a vida. No entanto, Soares; Miranda (2008) referem que mesmo neste contexto de "laminação das subjetividades, é possível singularizar no cotidiano, ensejando pequenas práticas que sejam focos de criatividade e de experiências de vida enriquecedoras das relações das pessoas com o mundo” (p. 10).

Assim, Maturana (2009) nos remete à operacionalidade da aceitação mútua,

\begin{abstract}
Biologicamente, as emoções são disposições corporais que determinam ou especificam domínios de ações. Convido-os a refletir sobre como vocês reconhecem suas próprias emoções e as dos outros. Se o fizerem, verão que vocês distinguem as diferentes emoções fazendo algum tipo de apreciação sobre o domínio de ações em que se encontra a pessoa ou o animal, ou fazendo uma apreciação sobre o domínio de ações que sua corporalidade conota (MATURANA, 2009, p. 16).
\end{abstract}

A vivência deste fato, no meio sociocultural, reflete ações fundadas nas emoções. Enfatizar estas emoções é permitir o fenômeno social da convivência, no qual o outro - o idoso - é aceito mutuamente, proporcionando, talvez, um bem-estar, pois "a constituição biológica humana é a de um ser que vive ao cooperar e no compartir (...)” (MATURANA, 2009, p. 97).

Assim, as ações e movimentos compartilhados entre o corpo do cuidador e o corpo que recebe os cuidados (os clientes idosos), serão construídos sob um olhar do mundo a partir das possibilidades, ou seja, prospectivo, valorizados nas suas habilidades e potencialidades, a despeito de suas limitações biológicas e sociais. O olhar será qualitativo e prospectivo para suas habilidades, capacidades, atividades e comportamento, ao contrário de quantitativo e retrospectivo, trazendo uma busca incessante de superação e de potencialidades, previamente estabelecidas, a priori, para quem cuida (referente à prevenção ou reabilitação).

\title{
3 DISCUSSÃO
}

Aimplantaçãoe implementaçãode um Programa de Prevenção e Reabilitação Fonoaudiológica, como ferramenta importante para a saúde pública, viabilizauma intervenção planejada e sistematizada nos clientes idosos que sofrem com o curso desta patologia (disfagia/presbifagia). Porém, acreditamosnum Programa de Prevenção e Reabilitação Fonoaudiológica que considere a emoção na disfagia em clientes idosos, deve: a) identificar como os idosos se sentem diante da presbifagia e que efeitos de ordem física e emocional são destacados como indicadores de intervenção e tratamento, podem ser instituídos para o alívio do sintoma de engasgar, conferido pelos clientes; b) caracterizar os efeitos das emoções sentidas pelos idosos diante da disfagia, apontando implicações e efeitos no programa implantado.

Também sabemos que, o terreno escolhido por nós para sustentar esse estudo, é movediço, numa linguagem “gaga”. E, por que não dizer 'estrangeira' para aqueles acostumados a pensar em doença e encontrar sinais e sintomas que justifiquem suas ações de cuidar.

Assim, estamos querendo encontrar, achar, capturar na subjetividade de cada idoso, as emoções que antecedem, que se instalam e permanecem após um evento - o engasgo - não só como sintoma, mas como um sentimento que freia seu modo de se alimentar e de viver saudavelmente.

\section{CONSIDERAÇÕES FINAIS}

Diante dessas considerações, acreditamos que caminharemos para uma construção e vigilância epistemológica e epidemiológica, procurando sistematizar as relações entre saúde e ciência. Não obstante, a busca por um conhecimento prudente (SANTOS, 2010) requer facultar a credibilidade dos conhecimentos científicos e não-científicos, explorando a pluraridade interna da ciência e interação de saberes. 


\section{REFERÊNCIAS}

BRASIL. MINISTÉRIO DA SAÚDE. Atenção à Saúde da Pessoa Idosa e Envelhecimento. Série Pactos pela Saúde, v.12. Brasília - DF, 2010.

CERVO, A.L.; BERVIAN, P.A.- Metodologia Científica - 5a ed.- São Paulo: Prentice Hall, 2002.

DELEUZE, G.; GUATTARI, F. Mil Platôs: capitalismo e esquizofrenia, vol. 4. Trad. Suely Rolink. São Paulo, 1997.

FIGUEIREDO, N.M.A.; MACHADO, W.C.A. Corpo \& Saúde: condutas clínicas de cuidar. Rio de Janeiro: Águia Dourada, 2009.

FIGUEIREDO, N.M.A.; SANTOS, I.; TAVARES, R. A Dimensão da Garantia do Cuidado à Pessoa Idosa. In FIGUEIREDO, N.M.A; TONINI, T. (org.). Gerontologia: atuação da enfermagem no processo de envelhecimento. $2^{\mathrm{a}}$ ed. São Paulo: Yendis, 2012.

FOUCAULT, M. O Nascimento da Clínica. São Paulo: Forense Universitária, 2003.

GUATTARI, F. As Três Ecologias. 21ª ed. São Paulo: Papirus, 2013.

GUATTARI, F.; ROLNIK, S. Micropolítica: cartografias do desejo. 4ª ed. Petrópolis: Vozes, 1996.

FERREIRA, V.J.A. Dislexia e Outros Distúrbios da Leitura-Escrita.In:Zorzi, J.;Capellini, S.Organização Funcional do Cérebro no Processo de Aprender. $2^{\mathrm{a}}$ ed.SãoJosé dos Campos: Pulso, 2009.

LEDOUX, J. Cérebro Emocional: os misteriosos alicerces da vida emocional. Trad. Terezinha Batista dos Santos. Rio de Janeiro: Objetiva, 2001.

MATURANA, H. Emoções e Linguagem na Educação e na Política. Belo Horizonte: UFMG, 2009.

MENDES et al. Disfagia. Prática baseada em evidências. IN: ANDRADE, C.R.F.; LIMONGI, S.C.O. Eficácia do Atendimento Fonoaudiológico em Indivíduos Adultos e Idosos com Diafagia - Hospital Geral. São Paulo: Sarvier, 2012.

MOLES, A.A. As Ciências do Impreciso. Trad. Glória de Carvalho Lins. Rio de Janeiro: Civilização Brasileira, 1995.

NAJMANOVICH, D. O sujeito encarnado: questões para pesquisa no/do cotidiano. Rio de Janeiro: DP \& A, 2001.

SANTOS, B.S. Para além do Pensamento Abissal: das linhas globais a uma ecologia de saberes. Revista Crítica de Ciências Sociais, $n^{\circ}$ 78, pp.3-46, 2007.

A Crítica da Razão Indolente. São Paulo: Cortez, 2010a.

SANTOS, M. A Natureza do espaço. São Paulo: Hucitec, 1999.

SEVERINO, A.J.- Metodologia do Trabalho Científico- 23ª ed.São Paulo: Cortez, 2007.

SOARES, L.B.; MIRANDA, L.L. Produzir subjetividades: o que significa? Disponível em: http: <www. revispsi.uerj.br/v9n2/artigos/html/v9n2a10.html> 2008. Acessoem 06/03/13.

VYGOTSKY, L.S.; LURIA, A.R.; LEONTIEV, A.N. Linguagem, Desenvolvimento e Aprendizagem. $10^{\mathrm{a}}$ ed. São Paulo: Ícone, 2006.

WAJNSZTEJN, A.C.; WAJNSZTEJN, R. Dificuldades Escolares: Um Desafio Superável. 2a ed. São Paulo:Artemis, 2009. 